\title{
Takotsubo Cardiomyopathy: Is It Due to Adrenal Crisis or Sjogren's Flare?
}

\author{
Mohinder Reddy Vindhyala, b, Venkata S Boppana ${ }^{a}$, Shravani Vindhyal ${ }^{\mathrm{a}}$
}

\begin{abstract}
Takotsubo cardiomyopathy is a form of reversible cardiomyopathy. It is usually due to sudden emotional or physical stress. It is associated with excessive sympathetic stimulation and catecholamine release. Patients have a very similar presentation to an acute coronary syndrome with patent coronaries. We present a case of takotsubo cardiomyopathy in a patient who has a history of Sjogren's disease on a steroid taper.
\end{abstract}

Keywords: Takotsubo; Cardiomyopathy; Reversible cardiomyopathy; Sjogren's disease

\section{Introduction}

Takotsubo cardiomyopathy is a well-known entity; it still continues to puzzle experts, especially in regard to the etiology. Stress-induced release of catecholamines is hypothesized to cause cardiac dysfunction. Two different pathophysiologies have been hypothesized to cause takotsubo. One being the endocrine mediated due to elevated plasma catecholamine level and the other due to neuronal hypothesis by triggering the sympathetic nervous end.

\section{Case Report}

A 64-year-old Caucasian lady with recently diagnosed Sjogren's disease and no prior history of coronary artery disease presented to the hospital with worsening fatigue and progressive generalized weakness over past few weeks. Review of systems was positive for diffuse joint pains; she denied shortness of breath, chest pain, palpitations, orthopnea or paroxysmal nocturnal dyspnea. Hypertension was her only chronic medical problem. She had quit smoking 5 years ago.

Manuscript submitted September 30, 2018, accepted October 23, 2018

aUniversity of Kansas School of Medicine-Wichita, 1010 N Kansas, Wichita, KS 67214, USA

${ }^{b}$ Corresponding Author: Mohinder Reddy Vindhyal, University of Kansas School of Medicine-Wichita, 1010 N Kansas, Wichita, KS 67214, USA.

Email: mvindhyal@kumc.edu

doi: https://doi.org/10.14740/cr759w
In the emergency department, she was found to be hypotensive with a blood pressure of $78 / 40 \mathrm{~mm} \mathrm{Hg}$; pulse rate was $100 / \mathrm{min}$, regular. Laboratory tests revealed acute kidney injury (blood urea nitrogen (BUN): $40 \mathrm{mg} / \mathrm{dL}$, creatinine: $3 \mathrm{mg} /$ $\mathrm{dL}$ ) and hyponatremia (sodium: $129 \mathrm{mEq} / \mathrm{L}$ ); potassium was $4.9 \mathrm{mEq} / \mathrm{L}$, chloride: $93 \mathrm{mEq} / \mathrm{L}$ and bicarbonate: $23 \mathrm{mEq} / \mathrm{L}$. Complete blood count, TSH and liver function tests were normal. Electrocardiogram (ECG) showed sinus tachycardia with a rate of $106 / \mathrm{min}$. On review of medications, it was discovered that she had recently been tapered off prednisone and had started feeling worse since then. The patient was treated empirically for adrenal crisis with "stress dose steroids" (100 mg hydrocortisone every $6 \mathrm{~h}$ ). She was hydrated aggressively with normal saline; initially she felt better, but a few hours later developed worsening shortness of breath. She was found to be in congestive heart failure. Pro-BNP was elevated at $30,000 \mathrm{pg} /$ $\mathrm{mL}$. She denied any chest pain or palpitations. EKG showed sinus rhythm and $\mathrm{T}$ wave inversion in anterolateral leads (Fig. 1). Echocardiogram showed left ventricular ejection fraction (LVEF) of $20-25 \%$ with anteroseptal, inferoseptal, apical, and inferolateral akinesis (Fig. 2). Cardiac enzymes were mildly elevated with a peak troponin of $1.7 \mathrm{ng} / \mathrm{mL}$, peak creatine kinase (CK) of $73 \mathrm{U} / \mathrm{L}$ and peak CK-MB of $10.74 \mathrm{ng} / \mathrm{mL}$. The patient was diagnosed as having non-ST elevation myocardial infarction (NSTEMI), and transferred to our institute for cardiac catheterization.

Cardiac catheterization revealed non-obstructive coronary artery disease and severely reduced left ventricular systolic function with an estimated LVEF of $20 \%$, along with wall motion abnormalities consistent with takotsubo cardiomyopathy on ventriculogram (Fig. 3). She was treated in the coronary care unit for heart failure with standard medical therapy and she improved gradually. She was transitioned from hydrocortisone to oral prednisone. She was subsequently discharged in a stable condition. She continues to follow up with a cardiologist and is doing well 6 months later with improved LVEF between $45-50 \%$.

\section{Discussion}

Takotsubo cardiomyopathy is an acute, non-ischemic, reversible cardiomyopathy first described by Japanese authors Dote and Sato in 1990 in a series of five patients [1]. Most of the patients are postmenopausal white women with the mean age of onset at 60 years [2]. Patients usually present with symptoms suspicious of acute coronary syndrome with mild elevation of 


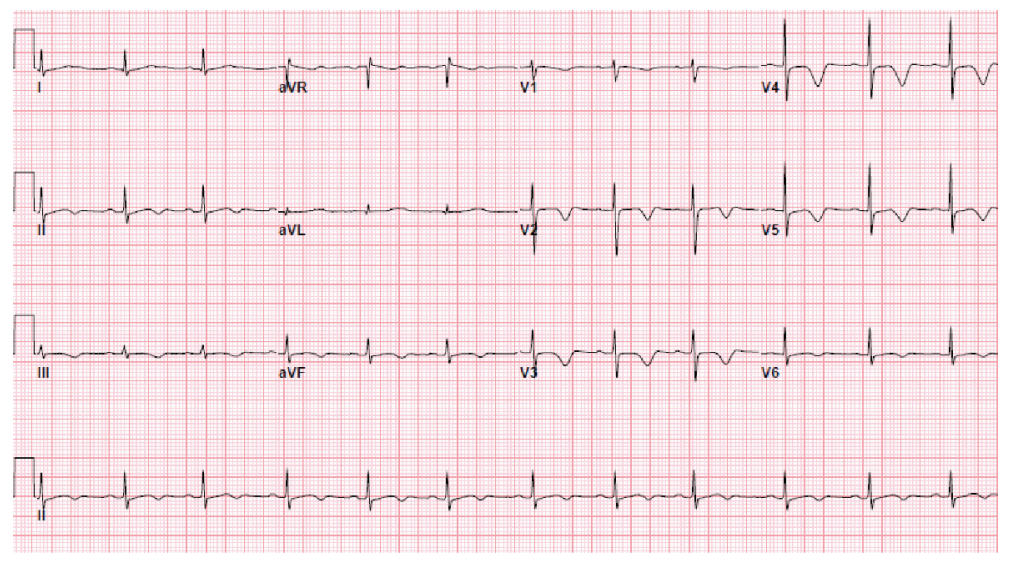

Figure 1. EKG showing sinus rhythm and T wave inversion in anterolateral leads.

cardiac biomarkers. EKG changes vary from ST elevation, T wave inversions in lateral leads, QT prolongation or transient Q waves. Cardiac catheterization reveals normal or non-obstructive coronaries. Ventriculography and echocardiography show transient hypokinesia or akinesia of the middle and apical regions of left ventricle and functional hyperkinesia of the basal region. This is usually in the setting of no recent head injury, intracranial hemorrhage, pheochromocytoma, myocarditis or hypertrophic cardiomyopathy [3].

The pathophysiology of takotsubo cardiomyopathy is still unclear and several mechanisms have been proposed. Since emotional or physiological stress has been seen in most cases, the most accepted hypothesis is that a catecholamine surge causes myocardial stunning $[4,5]$. The variability of stunning in the myocardial regions is explained by varied distribution of the beta receptors in different parts of the heart $[4,6]$ or by the high systolic apical circumferential wall stress $[7,8]$. Other proposed mechanisms include multivessel coronary artery spasm [8], ischemic theory with transient occlusion of left anterior descending artery [9] and coronary micro vascular dysfunction [10].

Our patient had tapered off her steroids (prednisone $10 \mathrm{mg}$

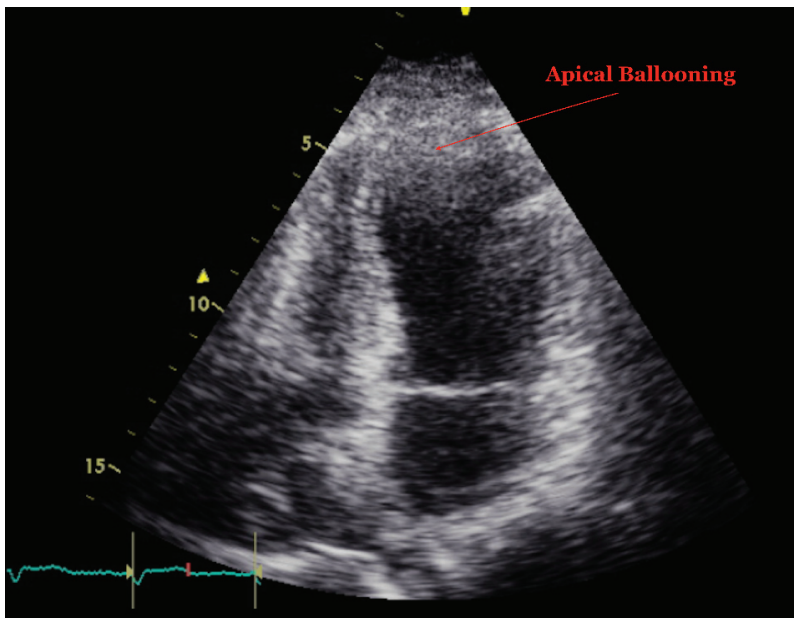

Figure 2. Echocardiogram at the time of presentation showing apical ballooning and relative hyperdynamic base. for 1 month followed by $15 \mathrm{mg}$ for 2 months) for Sjogren's disease precipitating adrenal crisis and a catecholamine surge that may have caused takotsubo cardiomyopathy, which she perceived as fatigue. Adrenal insufficiency secondary to adrenocorticotropic hormone (ACTH) deficiency [11] and Addison's disease [12] causing takotsubo has been described in the literature. Although the exact mechanism is unclear, compensatory systemic sympathetic overactivation is proposed as the underlying cause.

Another possibility is that a flare of Sjogren's disease post steroid taper might have led to the cardiomyopathy. To date, four similar cases have been reported in literature. Levin et al described congestive heart failure caused by reversible autoimmune myocarditis in a 48-year-old woman with primary Sjogren's syndrome [13]. The diagnosis was empirical as the myocardial biopsy specimen was inadequate. The patient responded well to steroids. Yoshioka et al diagnosed autoimmune myocarditis on gallium-67 scintigraphy in a 68 -year-old man in recent onset primary Sjogren's syndrome which resolved

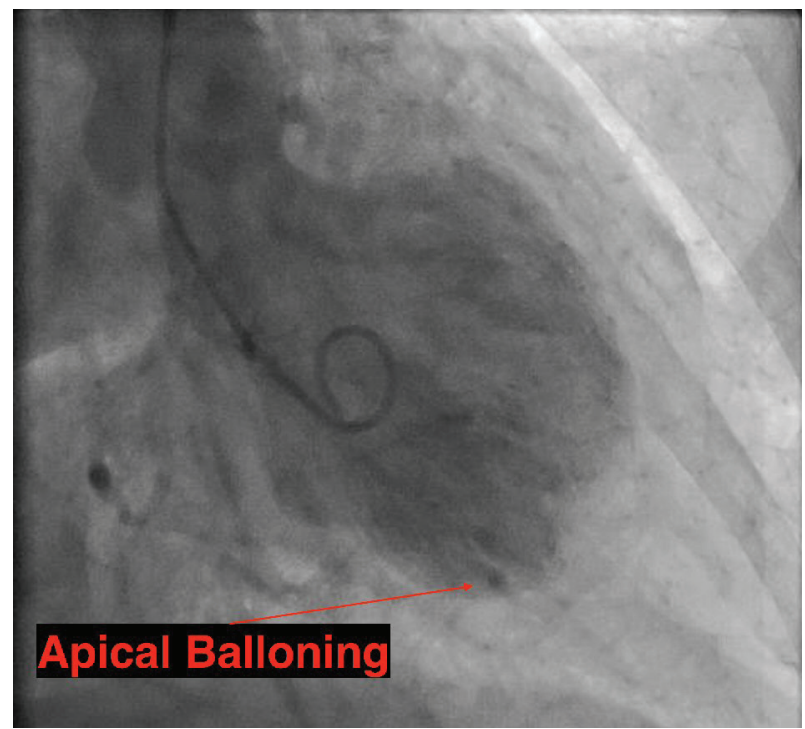

Figure 3. Left ventriculogram showing classic apical ballooning of takotsubo cardiomyopathy during catheterization. 
spontaneously [14]. More recently, Caballero-Gueto et al reported severe reversible cardiomyopathy in a 74-year-old lady which improved with steroids [15]. Golan et al described a 40-year-old woman with primary Sjogren's syndrome and systemic vasculitis with left ventricular hypokinesis on echocardiogram [16]. Leukocytoclastic small vessel vasculitis was seen in the cutaneous biopsy specimen. The rapidly deteriorating heart failure and other systemic complications remitted on pulse steroids and cyclophosphamide therapy. In the absence of autopsy confirmation, it is likely that these cases were in fact takotsubo (which has gained widespread awareness only recently) rather than autoimmune cardiomyopathy.

Apart from isolated case vignettes, there have been no systematic studies looking for an autoimmune etiology of takotsubo. Endomyocardial biopsy data on takotsubo cardiomyopathy is limited; however it does support the possibility as a few case series have shown the presence of mononuclear infiltrates in the endomyocardial biopsies of takotsubo patients. Wittstein et al reported a series of 19 patients out of which five underwent endomyocardial biopsy [5]. All five of them had mononuclear lymphocytic infiltrate. Another series of eight patients from Germany where serial biopsies were done, macrophages were seen in several extracellular clusters in "acute" biopsies along with an increased number of CD3 positive T-lymphocytes in comparison to "recovered" biopsies [17]. These studies suggest that there might be an autoimmune component to the etiology of takotsubo cardiomyopathy. However, there have been no systemic studies looking for the autoimmune etiology of takotsubo cardiomyopathy till date.

\section{Conclusions}

We described one of the not so common causes of takotsubo cardiomyopathy. This takotsubo cardiomyopathy may be due to the patient being tapered off her steroids causing catecholamine surge from the adrenal crisis or due to an autoimmune component which has not been described yet. Timely diagnosis, evaluation and management are crucial in treating such cardiomyopathy. Our patient has been symptom-free since the treatment.

\section{Conflict of Interest}

The authors have no conflicts of interest to disclose.

\section{References}

1. Dote K, Sato H, Tateishi H, Uchida T, Ishihara M. [Myocardial stunning due to simultaneous multivessel coronary spasms: a review of 5 cases]. J Cardiol. 1991;21(2):203214.

2. Castillo Rivera AM, Ruiz-Bailen M, Rucabado Aguilar L. Takotsubo cardiomyopathy - a clinical review. Med Sci Monit. 2011;17(6):RA135-147.

3. Kawai S, Kitabatake A, Tomoike H, Takotsubo Cardio- myopathy G. Guidelines for diagnosis of takotsubo (ampulla) cardiomyopathy. Circ J. 2007;71(6):990-992.

4. Ueyama T, Kasamatsu K, Hano T, Yamamoto K, Tsuruo Y, Nishio I. Emotional stress induces transient left ventricular hypocontraction in the rat via activation of cardiac adrenoceptors: a possible animal model of 'tako-tsubo' cardiomyopathy. Circ J. 2002;66(7):712-713.

5. Wittstein IS, Thiemann DR, Lima JA, Baughman KL, Schulman SP, Gerstenblith G, Wu KC, et al. Neurohumoral features of myocardial stunning due to sudden emotional stress. N Engl J Med. 2005;352(6):539-548.

6. Lyon AR, Rees PS, Prasad S, Poole-Wilson PA, Harding SE. Stress (Takotsubo) cardiomyopathy - a novel pathophysiological hypothesis to explain catecholamineinduced acute myocardial stunning. Nat Clin Pract Cardiovasc Med. 2008;5(1):22-29.

7. Dandel M, Lehmkuhl H, Knosalla C, Hetzer R. Left ventricular wall motion abnormality and myocardial dysfunction in stress cardiomyopathy: new pathophysiological aspects suggested by echocardiography. Int J Cardiol. 2009;135(2):e40-43.

8. Merli E, Sutcliffe S, Gori M, Sutherland GG. Tako-Tsubo cardiomyopathy: new insights into the possible underlying pathophysiology. Eur J Echocardiogr. 2006;7(1):5361 .

9. Ibanez B, Benezet-Mazuecos J, Navarro F, Farre J. Takotsubo syndrome: a Bayesian approach to interpreting its pathogenesis. Mayo Clin Proc. 2006;81(6):732-735.

10. Kurisu S, Inoue I, Kawagoe T, Ishihara M, Shimatani Y, Nishioka K, Umemura T, et al. Myocardial perfusion and fatty acid metabolism in patients with tako-tsubolike left ventricular dysfunction. J Am Coll Cardiol. 2003;41(5):743-748.

11. Ukita C, Miyazaki H, Toyoda N, Kosaki A, Nishikawa M, Iwasaka T. Takotsubo cardiomyopathy during acute adrenal crisis due to isolated adrenocorticotropin deficiency. Intern Med. 2009;48(5):347-352.

12. Punnam SR, Gourineni N, Gupta V. Takotsubo cardiomyopathy in a patient with Addison disease. Int J Cardiol. 2010;144(2):e34-36.

13. Levin MD, Zoet-Nugteren SK, Markusse HM. Myocarditis and primary Sjogren's syndrome. Lancet. 1999;354(9173):128-129.

14. Yoshioka K, Tegoshi H, Yoshida T, Uoshima N, Kasamatsu Y. Myocarditis and primary Sjogren's syndrome. Lancet. 1999;354(9194):1996.

15. Caballero-Gueto J, Rodriguez-Paiz C, Caballero-Gueto FJ, Ulecia-Martinez MA. [Severe reversible cardiomyopathy in primary Sjogren's syndrome]. Rev Esp Cardiol. 2007;60(3):326-327.

16. Golan TD, Keren D, Elias N, Naschitz JE, Toubi E, Misselevich I, Yeshurun D. Severe reversible cardiomyopathy associated with systemic vasculitis in primary Sjogren's syndrome. Lupus. 1997;6(6):505-508.

17. Nef HM, Mollmann H, Kostin S, Troidl C, Voss S, Weber M, Dill T, et al. Tako-Tsubo cardiomyopathy: intraindividual structural analysis in the acute phase and after functional recovery. Eur Heart J. 2007;28(20):2456-2464. 